\title{
DETERMINATION OF TOXICITY OF CHOPPED MEAT-BASED SEMI-PRODUCTS IN VIVO
}

\author{
Maria Paska \\ Department of Technology of Meat, Meat and Oil and Fat Products \\ Lviv National University of Veterinary Medicine and Biotechnology named after S. Z. Gzhytsky \\ 50 Pekarska str., Lviv, Ukraine, 79010 \\ maria_pas@ukr.net \\ Ulyana Drachuk \\ Department of Technology of Meat, Meat and Oil and Fat Products \\ Lviv National University of Veterinary Medicine and Biotechnology named after S. Z. Gzhytsky \\ 50 Pekarska str., Lviv, Ukraine, 79010 \\ ul.drachuk@gmail.com \\ Olga Masliichuk \\ Department of technology of meat, meat and oil and fat products \\ Lviv National University of Veterinary Medicine and Biotechnology named after S. Z. Gzhytsky \\ 50 Pekarska str., Lviv, Ukraine, 79010 \\ olia_maruniak@ukr.net \\ Volodymyr Vovk \\ Department of technology of meat, meat and oil and fat products \\ Lviv National University of Veterinary Medicine and Biotechnology named after S. Z. Gzhytsky \\ 50 Pekarska str., Lviv, Ukraine, 79010 \\ vovk1805@gmail.com
}

\footnotetext{
Abstract

At solving the problem of protein deficiency, the great role of the raw material for its production is played by leguminous cultures such as peas, haricot beans, lupine, forage beans, lentil, chick-peas, peavine and other. The chemical composition and food value of proteins of these cultures are most close to animal proteins - of meat, fish and also milk. Among the essential quantity of vegetable raw material that contains protein (33-50\%), the special place is occupied by lupine, characterized as an important reserve of high-quality protein substances at the World congress in 1991 in the USA [1].

There were elaborated certain recipes of meat chopped semi-products, based on beef that contains $5 \%, 10 \%, 15 \%$ of lupine flour and $0,5 \%$ of elecampane root powder.

There were carried out the studies on the determination of toxicity of functional raw material and cutlets with $10 \%$ content of lupine flour and $0,5 \%$ of elecampane on white mice organisms. There were used methods, based on toxic substances extraction from forages and peeled gains under condition of the intra-stomach administration and cutlets feed during 10 days. Blood was taken for hematological studies in mice, fed by functional cutlets.

It was proved, that these products have no toxic influence on organisms. At the pathoanatomical dissection, any macroscopic changes in tissues were not revealed, blood hematological results are within norm.

The best sample No. 2 with $10 \%$ content of lupine flour and $0,5 \%$ of elecampane was determined by the gustatory method.

It was determined, that functional meat chopped semi-product may be included in the ration for the sound, treating-prophylactic nutrition.

Keywords: chopped meat semi-products, toxicity of a product, in vivo conditions, functional cutlets, protein deficiency.

\section{Introduction}

The problem of ecological, sound balanced nutrition is extremely urgent. For today meat products manufacture needs to use diverse meat raw material. As far as the modern nutrition conception it is not a fashionable tendency and demand of time, it is absolutely expedient to introduce new functional products with given treating-prophylactic properties on the market. 
Meat chopped semi-products consumption is an important part of the food ration of the population. It became expedient to search for new sources of full value protein and introduce new types of products with the high food value. Lupine occupies the special place among the essential quantity of vegetable raw material [1]. Manufacture of meat chopped semi-products that combine meat raw material and vegetable proteins in their recipe and contain full value proteins gains the special urgency, so the necessity to elaborate new functional recipes appears.

Today scientists face the task to elaborate functional products with the protein content, because almost $25 \%$ of population suffers from protein deficiency problems [1].

Cutlets are the main part of Ukrainians' meat ration that is why protein functional cutlets consumption will partially satisfy the need of the population in full value protein.

At the world congress in the USA lupine was characterized as an important reserve of high quality protein substances [2]. Alongside with protein, lupine seeds contain 25-40\% of nitrogen-free extractive substances, up to $9 \%$ and more fat, 3-4\% of ash. The mean content of protein in lupine flour is 38,6\% of dry substances (DS) that 3 times exceeds this index for wheat flour of I sort and by $2,2 \%$ of DR - for soy flour [2,3]. Near $90 \%$ of protein substances of the general content in lupine seeds are presented by easily assimilated fractions - albumins and globulins, whereas in soy flour - only $67 \%$. [4].

Elecampane, or mullein, elecampane root, gallagan it is a perennial herbaceous plant. Rhizomes with roots that have the strong special smell and spicy a bit bitterish taste in the dry state are used in medicine. Rhizomes and roots of elecampane contain the compound essential oil (lactones, alantol and proazulen). Alongside with the essential oil there were found inulin (up to $44 \%$ ), inulenin, pseudoinulin, acetic and benzoic acids [5]. This plant is used at headaches, epilepsy and tachycardia. It has the expressed expectorant and anti-inflammatory effect, is used at bronchitis, pneumonia, bronchial asthma, tuberculosis and whooping cough. Elecampane is effective as an antiinflammatory means at gastritis, colitis, hepatic diseases and ones of the bilious bladder, urinary tracts. It normalizes the work of the stomach at both diarrhea, caused by the chronic enterocolitis and usual constipations, is effective at painful menstruations. The elecampane root is an effective means at rheumatoid diseases and metabolic ones: podagra, non-specific arthritis and exudation diathesis. It was also proved, that elecampane favors the renewal of metabolic processes, forces, cheerfulness, youth and health $[3,5]$.

So, meat chopped semi-products manufacture is provided by lupine flour introduction as a valuable protein product and elecampane root powder as a medicinal-technical raw material.

The aim of the work is to create functional non-toxic chopped semi-products for solving protein deficiency problems.

The main tasks of the research are:

- to elaborate recipes of functional meat chopped semi-products, adding lupine flour, replacing the meat part and elecampane root powder as a spicy-aromatic raw material;

- to study the toxicity of the raw material and cutlets on white laboratory mice;

- to determine the best sample by the gustatory method.

\section{Materials and methods}

The correspondent methods ("Method of the determination of the toxicity of shots, oilcakes and forage yeast" and "Methods of the determination of the toxicity on laboratory animals") were realized in the Laboratory of pharmacology and toxicology and Laboratory of clinical-biological studies of the State scientific control institute of veterinary preparations and food additives (Lviv, Ukraine).

The experiments on the toxicity of the raw material and products were realized on white mice under conditions on intra-stomach administration, and feeding cutlets with $10 \%$ lupine flour and $0,5 \%$ of elecampane during 10 days.

\section{1. The recipe and technology of functional cutlets with lupine flour and elecampane}

Seeds of lupine "Kharchoviy", peeled and grinded to $150 \mathrm{mcm}$, are used. Flour looks as homogenous fine-dyspersated of light-yellow powder, of neutral smell and taste. Dry roots and rhizomes of elecampane are grinded to $200 \mathrm{mcm}$ and sieved through the sieve, made of a wire 
woven net No. 095.The smell of elecampane is strong, taste - bitterish-spicy. The dry high-quality raw material must have the humidity no more than $13 \%$, total ash - no more than $10 \%$, organic admixture - no more than $0,5 \%$, mineral admixture - no more than $1 \%$. At the stage of mixing forcemeat is added with lupine flour and elecampane root powder.

The recipes of functional meat chopped semi-products were elaborated: sample No. 1 contained $5 \%$ of lupine flour instead of meat raw material, and $0,5 \%$ of elecampane root powder as a medicinal-technical raw material; sample No. 2 contained $10 \%$ of lupine flour and $0,5 \%$ of elecampane, and sample No. 3 contained $15 \%$ of lupine flour and $0,5 \%$ of elecampane. The control sample of ready semi-products corresponded to requirements of SST R 52675-2006. The recipe is presented in Table 1.

Table 1

Recipe of meat chopped semi-products with functional additives

\begin{tabular}{ccccc}
\hline & \multicolumn{3}{c}{ Raw material consumption for 100 kg of ready products, $\mathbf{k g}$} \\
Raw material name & \multicolumn{3}{c}{ Netto } & Sample No. 3 \\
\hline Beef (cutlet meat) & Control & Sample No. 1 & Sample No. 2 & 45,9 \\
Lupine flour & 54,0 & 51,3 & 48,6 & $\mathbf{8 , 1}$ \\
Raw-fat & - & $\mathbf{2 , 7}$ & $\mathbf{5 , 4}$ & 5,0 \\
Wheat bread & 5,0 & 5,0 & 5,0 & 13,0 \\
Breading rusks & 13,0 & 13,0 & 13,0 & 2,0 \\
Onion & 2,0 & 2,0 & 2,0 & 3,0 \\
Grinded black pepper & 3,0 & 3,0 & 3,0 & 0,05 \\
Elecampane powder & 0,1 & 0,05 & 0,05 & $\mathbf{0 , 0 5}$ \\
Food salt & - & $\mathbf{0 , 0 5}$ & $\mathbf{0 , 0 5}$ & 1,2
\end{tabular}

\section{2. Determination of the toxicity under conditions of the intra-stomach administration of the extract}

The study of the toxicity of lupine flour, elecampane and functional cutlets was realized on white mice, according to the "Method of the determination of the toxicity of shots, oilcakes and forage yeast" (accepted 28.12.1979). This method is based on the extraction of toxic substances from forage and peeled gains. Under conditions of intra-stomach administration, toxins cause the hemorrhagic inflammation of the gastrointestinal tract or death of mice $[6,7]$.

According to this method, the batch of the raw material (lupine flour, elecampane, cutlets $5 \%, 10 \%, 15 \%$ ) with weight $100 \mathrm{~g}$ were put in the flask with the rubbed cork poured with acetone $(300 \mathrm{ml})$ and extracted at shaking on the shuttle-apparatus for 3 hours: Fig. 1. The extract was filtered through paper filters in the cup for evaporation and added with $2,5 \mathrm{ml}$ of sunflower oil. Acetone was evaporated on the water bath at the temperature $50{ }^{\circ} \mathrm{C}$ under the air-ejecting chamber till the acetone smell disappeared.

5 white mice with the mass 19-21 g were used for the experiment. They were kept on the starvation diet for 5 hours and one time administered with $0,5 \mathrm{ml}$ of the extraction by the probe perorally in the stomach.

The control group of mice (5 animals) was administered with oil, used for dissolving the extract. In 3 days of observation white mine were poured with chloroform and dissected: Fig. 2. 


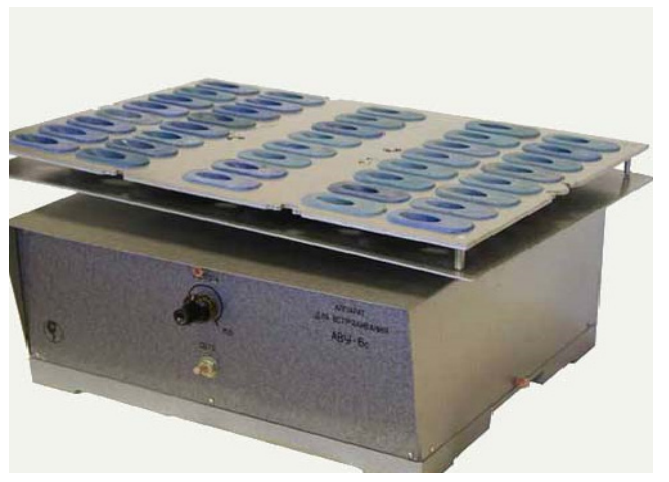

Fig. 1. Shuttle-apparatus for raw material shaking

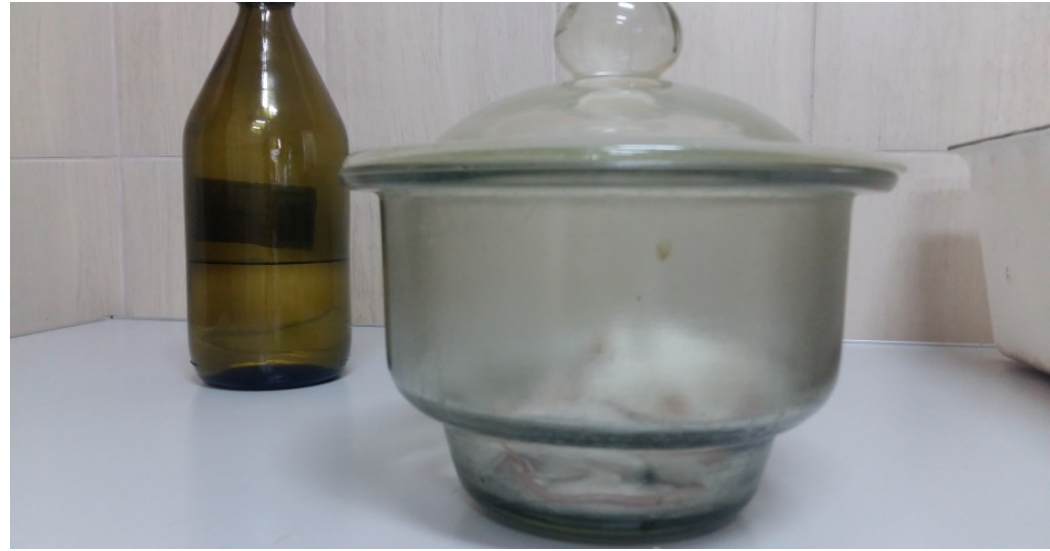

Fig. 2. Pouring of laboratory mice

The toxicity was assessed by the following criteria:

- Lupine, elecampane and functional cutlets are not toxic - mice are alive, pathoanatomical changes are not revealed at the dissection of killed animals;

- Lupine, elecampane and functional cutlets are a bit toxic - mice are alive, the hemorrhagic inflammation of the gastrointestinal tract, most often nidal one, is revealed at the dissection of killed animals;

- Lupine, elecampane and functional cutlets are toxic - all or even only one mouse die, and the hemorrhagic inflammation of the gastrointestinal tract, in most cases accompanied by the liver or kidney degeneration or hemorrhages in parenchymatous organs, is observed at the dissection of died or killed mice.

\section{3. Determination of the toxicity of ready $10 \%$ cutlets under conditions of feeding to white mice as the main forage during 3 days}

The determination of the toxicity of functional cutlets that contain $10 \%$ of lupine flour and $0,5 \%$ of elecampane root was realized according to the "Methodology of the toxicity determination on laboratory animals" by feeding cutlets to white mice with the mass 20-23 g [8]. Cutlets were introduced in the day ration, quantitatively replacing forage in the ration composition ( $100 \mathrm{~g}$ every day were replaced by fresh cutlets). The feeding was realized 10 days without interruption. Before the experiment mice were kept hungry for 5 days (water was not limited). 20 animals (10 control ones) were taken for the experiment, they were clinically observed.

The toxicity indicators are: the loss of alive mass, disorders of the gastrointestinal tract and central nervous system (inhibition or excitation, disorder of movement coordination, convulsions, paralysis). If death doesn't take place after 10 days of feeding, mice are killed and dissected. At the intoxication, the catarrhal inflammation of the gastrointestinal tract, hemorrhages and also degenerative changes in parenchymatous organs are revealed. 


\section{4. Hematological studies}

Blood samples for hematological studies were taken in 24 hours after 10 days of feeding ready cutlets to mice at decapitation: Fig. 3.

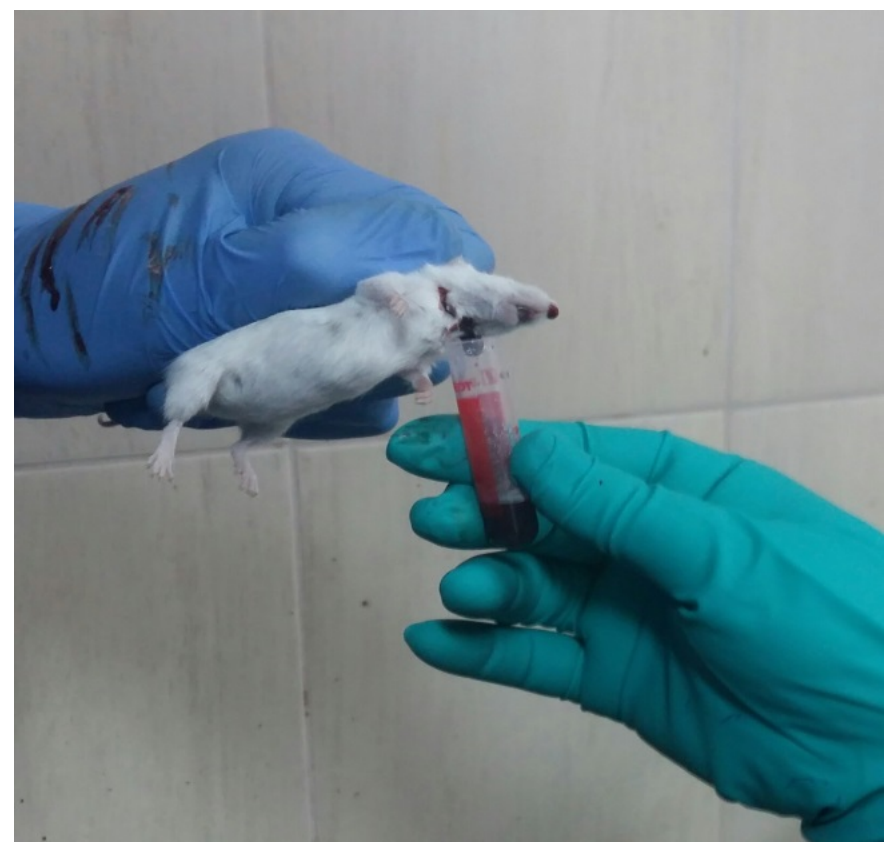

$a$

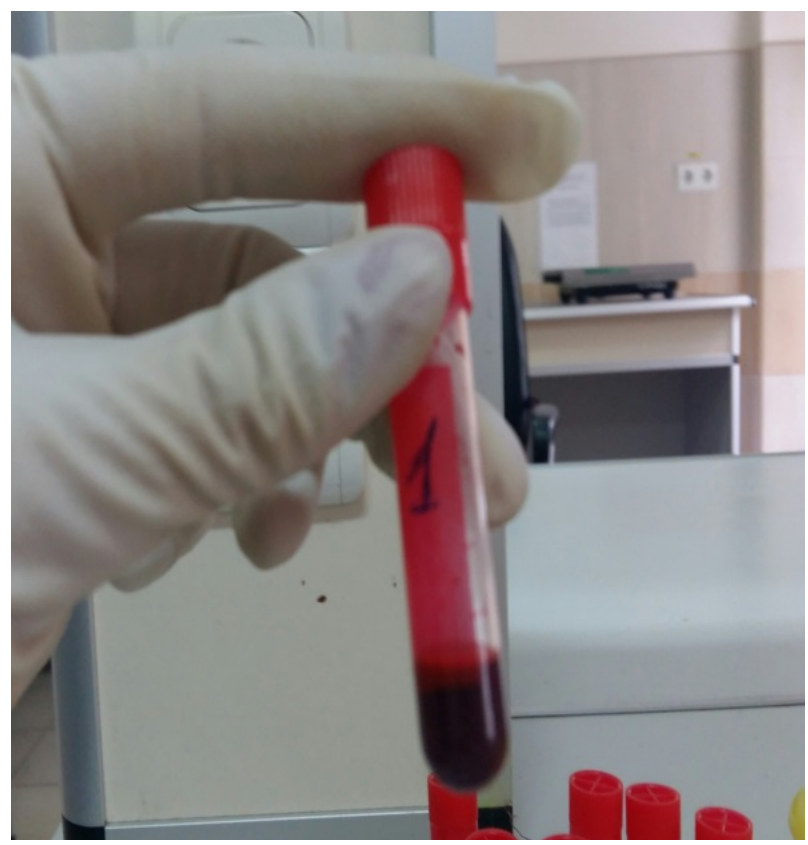

$b$

Fig. 3. Taking of blood samples of mice: $a$-decapitation and taking of blood; $b$ - taken blood sample

The differentiated calculation of types of leucocytes in smears of peripheral blood of animals was realized after coloration by the method of Romanovsky-Giemsa [9]. Blood samples were studied at the very day of reception. Blood for hematological studies, taken in test tubes with potassium ethylene-diamin tetra-acetic acid (KABE Labortechnik), analyzed on the automatic hematological analyzer Mythic 18, Switzerland. The fraction composition of proteins of blood plasma of mice was determined by Vlizlo conventional methods [10]. The statistical processing of obtained data was realized using MS Excel 5.0. Data were presented as a mean value \pm mistake of a mean value $(\mathrm{M} \pm \mathrm{m})$. The analysis of the reliability of experimental results was realized using the one-factor dispersed analysis (ANOVA). The difference between indices was considered as statistically reliable at the value $\mathrm{p}<0,05$.

\section{5. Tasting of products}

Tasting of elaborated functional cutlets was realized at the department of "Meat, meat and oil-fat products" of Lviv national university of veterinary medicine and biotechnologies, named after S. Z. Gzhytsky (lviv, Ukraine): Fig. 4.

The determination of the quality of ready products was realized by the organoleptic assessment of each parameter - look, smell, taste, juiciness, consistence - by marks 5, 4, 3, 2. The assessment criteria: mark 5 was put to cutlets that correspond to set requirements and indices by the look, taste, smell, consistence and color. Products with perfect taste indices but with deviations in form, not enough ruddy crust, cracks on the surface, incomplete raw material set and other insignificant deviations are assessed as 4 . Mark 3 was put to products that can be realized without processing, if their taste qualities don't correspond to all set requirements. Mark 2 was put to products with unusual taste and smell, enough salted, soured, bitter, spicy, without the proper form, burnt, with spoilage signs and so on. 


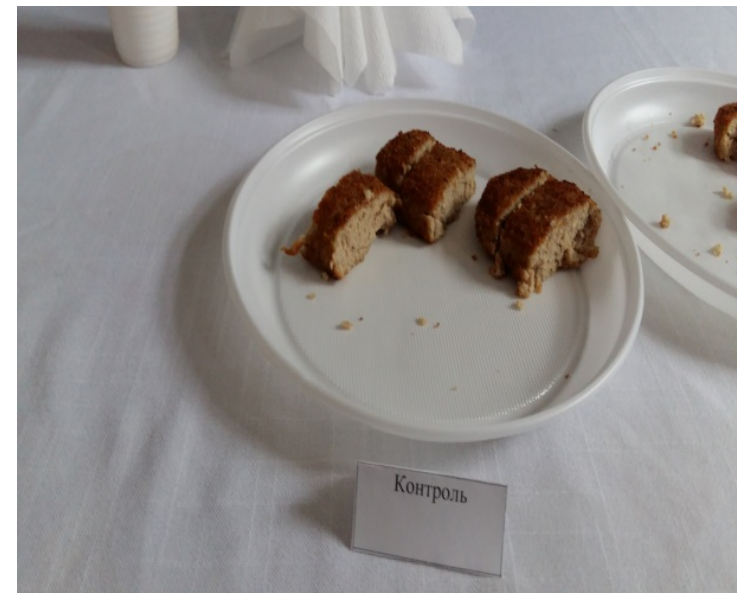

$a$

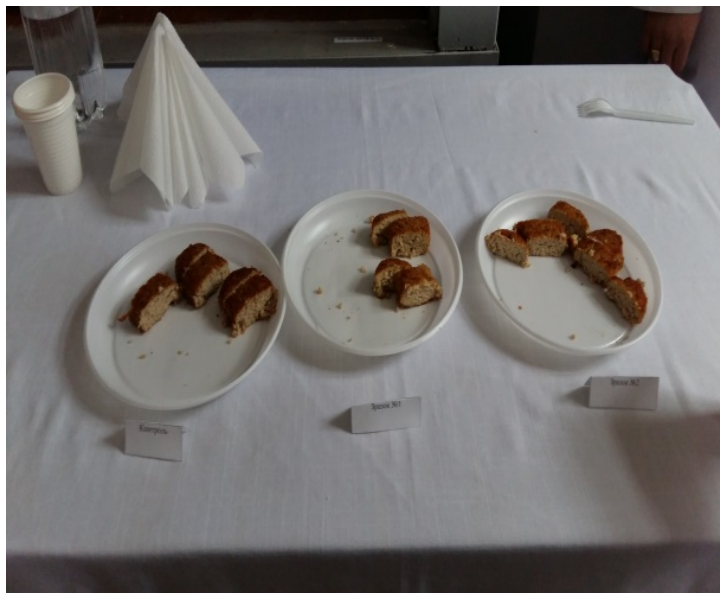

b

Fig. 4. Tasting of functional cutlets: $a$ - look of control cutlets; $b$ - look of elaborated samples

Having analyzed all parameters by correspondent criteria, the highest results were established, 12 experts took part in the experiment.

\section{Results of researches}

There were elaborated 3 recipes of functional cutlets that included: cutlet beef, raw fat, onion, wheat bread, water, breading rusks, salt, pepper. Meat part was replaced for $5 \%$ of lupine flour in sample No. 1 , for $10 \%$ - in sample No. 2 , and for $15 \%,-$ in sample No. 3 , and all samples were added with $0,5 \%$ of elecampane, replacing the part of black pepper.

At determining the toxicity of the raw material and cutlets, there were established: animals' death was not observed during 3 and 10 days; hair cover - shiny, even, lesions were absent; natural orifices without secretions, closed; hypodermic tissue was well developed; placing of internal organs of chest and abdominal cavity - anatomically right; changes of mass of internal organs $\mathrm{p}<0,05$, that is within norm. Visible macroscopic changes of organs were not revealed. The results of hematological studies of blood, namely: morphological indices, content of leucocytes and leuco gram, biochemical indices were within norm.

The elaborated samples have rather high organoleptic and taste qualities. The addition of lupine flour has no negative influence on products formation. Flour absorbs moisture well and makes cutlets juicy.

The results of tasting of elaborated meat functional cutlets are presented in Table 2.

Table 2

Assessment of tasting of meat functional cutlets

\begin{tabular}{ccccccccc}
\hline \multirow{2}{*}{ No. } & Product name & Look & Color & Smell & Consistence & Taste & Juiciness & General mark in points \\
\hline 1 & control & 5,0 & 5,0 & 5,0 & 4,5 & 5,0 & 4,5 & 4,83 \\
2 & Sample No. 1 & 4,8 & 5,0 & 5,0 & 4,5 & 5,0 & 4,5 & 4,80 \\
$\mathbf{3}$ & Sample No. 2 & $\mathbf{4 , 8}$ & $\mathbf{5 , 0}$ & $\mathbf{5 , 0}$ & $\mathbf{4 , 8}$ & $\mathbf{5 , 0}$ & $\mathbf{5 , 0}$ & $\mathbf{4 , 9 3}$ \\
4 & Sample No. 3 & 4,0 & 4,6 & 4,6 & 4,0 & 4,0 & 4,0 & 4,2
\end{tabular}

The highest results were obtained by sample No. 2 that contained $10 \%$ of lupine flour and $0,5 \%$ of elecampane.

The content of $10 \%$ of lupine flour and $0,5 \%$ of elecampane enrich products with enough protein, they are economically profitable, don't worsen taste qualities of functional cutlets. The in- 
crease of the content of lupine flour makes cutlets dry and fragile, and elecampane increase makes them bitterish.

\section{Conclusions}

At the assessment of toxicity criteria, it was established, that lupine flour, elecampane and functional cutlets are not toxic, mice are alive, pathoanatomical changes are not revealed in killed animals at dissection, hematological blood results are within norm.

There were elaborated 3 recipes for functional meat chopped semi-products on the beef base that contained $5 \%, 10 \%, 15 \%$ of lupine flour and $0,5 \%$ of elecampane.

It was established, that the best sample of functional cutlets is No. 2 with $10 \%$ content of lupine flour and $0,5 \%$ of elecampane.

It is recommended to introduce meat copped semi-products into the human ration to solve protein deficiency problems.

Beef functional cutlets may be widely used in fast food, and to change stereotypes about the harmfulness of "street food". The possible directions of this research development will be the widening of the assortment of meat products with the lupine share, namely sausages, frankfurters, meat dumplings and khinkali with meat-lupine stuffing.

\section{References}

[1] Arsenyev, L., Bondar, N., Golovchenko, O. (2003). Use of lupine seeds for the production of high-protein foods. Herald of DonDUET, 1 (17), 79-83.

[2] Paska, M., Masliichuk, O. (2015). Liupynove boroshno - vysokobilkovyi zbaghachuvach kharchovykh produktiv. Prodovolcha industriia APK, 6, 37-40.

[3] Paska, M., Masliichuk, O. (2016). Mikrobiologhichna ta spozhyvcha kharakterystyka miasnykh posichenykh napivfabrykativ $\mathrm{z}$ dodavanniam luupynovogho boroshna ta dyvosylu. Naukovyi visnyk LNUVM ta BT im. S. Z. Ghzhyckogho, 18 (4), 121-123.

[4] Feldheim, W. (2000). The use of lupins in human nutrition. Lupin, an ancient crop for the new Millenium. Proceedings of the 9-th International Lupin Conference. Auburn: Auburn University, 434-437.

[5] Kuzyk, T. (2013). New functional fermented milk product «Dyvosil». Experimental Station of Medicinal Plants. Institute of Nutrition and Nutrition Sciences. View «ESEN», 149-151.

[6] Kosenko, M., Kotsyumbas, I., Velichko, V. (1999). Toxicological control of feed and feed additives. Lviv: Triad plus, 118.

[7] Kotsiumbas, I., Malik, O., Paterega, I. et. al.; Kotsiumbas, I. (Ed.) (2006). Preclinical studies of veterinary medicines. Lviv: Triad plus, 360.

[8] Ludzik, B., Lapovets, L., Swan, G. (2011). Clinical laboratory diagnostics. Kyiv: Medicine, 287.

[9] Commission of the European Communities: Council Directive of 18 December 1986 on the Lows, regulating the Application of Principles of Good Laboratory Practice and the Verification of Their Applications for Tests on Chemical Substances (87/18/EEC) (1991). The Rules Governing Medicinal Products in the European Community, 1, 145-146.

[10] Vlizlo, V. V., Fedoruk, R. S., Makar, I. A. et. al. (2004). Fiziologo-biokhimichni metody doslidzhen’ u biologii, tvarynnytstvi ta veterynarniy medytsyni. Lviv: «VMS», 399. 